\title{
Factors Associated with Chronic Obstructive Pulmonary Diseases in Nepal: Evidence from a Nationally Representative Population-Based Study
}

\author{
Khem Bahadur Karki ${ }^{1-3, *}$ \\ Anil Poudyal (iD) ${ }^{1} *$ \\ Namuna Shrestha (D) \\ Namra Kumar Mahato' \\ Krishna Kumar Aryal ${ }^{4}$ \\ Milesh Jung Sijapati ${ }^{5}$ \\ Bihungum Bista' \\ Nitisha Gautam ' \\ Ranjeeta Subedi iD ' \\ Noor Kutubul Alam \\ Siddiquee (iD ${ }^{6}$ \\ Pradip Gyanwali \\ Ulrich Kuch (iD ${ }^{3}$ \\ David A Groneberg ${ }^{3}$ \\ Anjani Kumar Jha' \\ Meghnath Dhimal ${ }^{1,3}$ \\ 'Nepal Health Research Council \\ (NHRC), Kathmandu, Nepal; \\ ${ }^{2}$ Department of Community Medicine, \\ Maharajgunj Medical Campus, \\ Kathmandu, Nepal; ${ }^{3}$ Institute of \\ Occupational, Social and Environmental \\ Medicine, Goethe University, Frankfurt \\ am Main, Germany; ${ }^{4}$ Monitoring \\ Evaluation and Operational Research \\ (MEOR) Project, Abt Associates, \\ Kathmandu, Nepal; ${ }^{5}$ KIST Medical \\ College, Lalitpur, Nepal; ' ${ }^{6}$ ublic Health \\ Foundation of India, Bangalore, India \\ *These authors contributed equally to \\ this work
}

Correspondence: Anil Poudyal Email poudyalanil123@gmail.com
Background: The Global Burden of Diseases Study 2017 predicted that chronic obstructive pulmonary disease (COPD) is the second leading cause of death, the fourth leading cause of premature death, and the third cause for DALYs lost in Nepal. However, data on the populationbased prevalence of COPD in Nepal are very limited. This study aims to assess the prevalence of COPD and factors associated with the occurrence of COPD in Nepal.

Methods: From a nationally representative, population-based cross-sectional study on chronic non-communicable diseases, the prevalence of COPD and its associated factors was determined. Of 12,557 participants aged over 20 years, 8945 participants completed a questionnaire and spirometry. Eligible participants were also asked to answer a COPD diagnostic questionnaire for screening COPD cases, and if needed underwent prebronchodilator and post-bronchodilator spirometry. COPD was defined as a postbronchodilator FEV1/FVC (forced expiratory volume in $1 \mathrm{~s} /$ forced vital capacity) ratio of $<0.70$. Multivariate logistic regression was performed to identify factors associated with COPD. Sampling weights were used for all data analyses.

Results: The prevalence of COPD in Nepal was $11.7 \%$ (95\% CI: $10.5 \%$ to $12.9 \%$ ), which increased with age, and higher in those with a low educational level, those who had smoked $\geq 50$ pack-years, persons having a low body mass index (BMI), and residents of Karnali province. Multivariate analysis revealed that being aged 60 years and above, having a low BMI, low educational status, having smoked more than 50 pack-years, provincial distribution, and ethnicity were independent predictors of COPD.

Conclusion: COPD is a growing and serious public health issue in Nepal. Factor such as old age, cigarette smoking, low educational attainment, low BMI, ethnicity, and locality of residence (province-level variation) plays a vital role in the occurrence of COPD. Strategies aimed at targeting these risk factors through health promotion and education interventions are needed to decrease the burden of COPD.

Keywords: COPD, prevalence, non-communicable diseases, Nepal

\section{Background}

Chronic obstructive pulmonary disease (COPD) is a major public health problem and one of the major causes of chronic morbidity and mortality worldwide. ${ }^{1}$ According to the Global Burden of Disease (GBD) study, the prevalence of COPD was 3919 per 100,000 population globally and it was the third leading cause of global mortality in 2017.2,3 More importantly, COPD is a major killer in low- and middle-income countries (LMICs) where more than $90 \%$ of COPD deaths occur. ${ }^{4}$ Furthermore, COPD-associated mortality is predicted to increase by $160 \%$ 
in the Southeast Asian region in the coming decades. ${ }^{5}$ The economic impact of COPD among LMICs is also expected to increase to $£ 1.7$ trillion by 2030 . $^{6}$ As per the GBD 2017 prediction, COPD is the second leading cause of death in Nepal, the fourth leading cause of premature death, and the third cause for disability-adjusted life years (DALYs) in Nepal. ${ }^{1}$ In Nepal, some subnational, largely hospitalbased studies have yielded a prevalence of COPD ranging from $23 \%$ to $43 \% .^{7-9}$ A systematic analysis of the GBD Study by Soriano et al identified Nepal as one of the four countries with the highest age-standardized DALYs due to COPD in 2015. ${ }^{10}$ A hospital-based study conducted among non-specialist institutions in Nepal showed COPD as the most $(43 \%)$ common condition among outpatients followed by cardiovascular disease. ${ }^{7}$ Taken together, this evidence suggests that the anticipated increase in the prevalence of COPD may further strain the health care systems of Nepal.

Being a multi-etiological disease condition, COPD is associated with several causal risk factors. ${ }^{11}$ In Nepal, the prevalence and risk factors for COPD are expected to be high due to growing exposure, for example, to a high smoking rate and relatively high levels of air pollution. $^{12-15}$

It has been shown that the reported prevalence of COPD varies around the globe mainly due to the use of different sampling methods, diagnostic criteria, and measurement modalities. ${ }^{16}$ Amidst a dearth of evidence, the objective of this study is to determine the prevalence and associated risk factors of COPD in adults living in Nepal. It is the first national population-based prevalence study aimed at determining both the prevalence of COPD, through objective measurement using spirometry, and the associated determinants of this disease. The findings of this study will be important for informing health policy makers and health care providers aimed at improving the prevention and management of NCDs in Nepal in line with the global $25 * 25$ target adopted by the World Health Organization and the health-related Sustainable Development Goal 3. ${ }^{17}$

\section{Methods}

\section{Study Design and Subjects}

This study has used data from the prevalence study of selected chronic non-communicable diseases in Nepal. This is a population-based, nationwide cross-sectional survey conducted from 2016 to 2018 in all seven provinces of
Nepal. Data were collected through a multistage cluster sampling with a mix of probability proportionate to size (PPS) and systematic random sampling. The detailed methodology has been presented elsewhere. ${ }^{18}$ Males and females aged $\geqslant 20$ years and residents in the study area for at least the last 6 months were eligible for participation in the study. One participant out of the eligible candidates in each selected household was selected to take part in the survey using the Kish method. ${ }^{19}$ Research participants who had reported any eye, thoracic or abdominal surgery in the last two months, history of recent documented coronary artery disease (CAD), cough, hemoptysis, or pregnancy, were not included for spirometry. Of 13,200 participants who were approached for an interview, 12,557 accepted. Among 12,557 participants, only 8945 participants $(67.8 \%)$ performed the spirometry test at an acceptable level. Figure 1 shows the flow diagram of the study conducted. The study was carried out following the principles of the Declaration of Helsinki. The ethical principles of respect, beneficence and justice were maintained throughout the data collection process. Ethical approval was received from the Ethical Review Board of Nepal Health Research Council (NHRC). Written informed consent from participants was ensured after informing the study participants about the objectives of the study and their rights to decline or withdraw from the study. The confidentiality and anonymity of the participants were maintained by assigning unique identification codes.

\section{Data Collection Procedures}

All recruited participants were invited to participate in the study at a convenient and accessible site or at home. The trained interviewers conducted face-to-face interviews using a standardized questionnaire to collect information about participants' socio-demographic and past medical history. For assessing COPD, trained interviewers administered the standardized COPD Diagnostic Questionnaire to screen participants for spirometry. ${ }^{20,21}$ After an eligibility evaluation for spirometry, the interviewers took the participants through spirometry examination. Participants with airflow limitation $(\mathrm{FEV} 1 / \mathrm{FVC}<0.70)$ were further examined with post-bronchodilator spirometry.

\section{Spirometry and Diagnostic Criteria}

Spirometry was performed using Spirolab III ${ }^{\circledR}$ model color LCD (MIR, Rome, Italy) to measure pulmonary functions. Three best spirometry readings, out of which the best two were within $200 \mathrm{~mL}$ of each other, were taken from each 


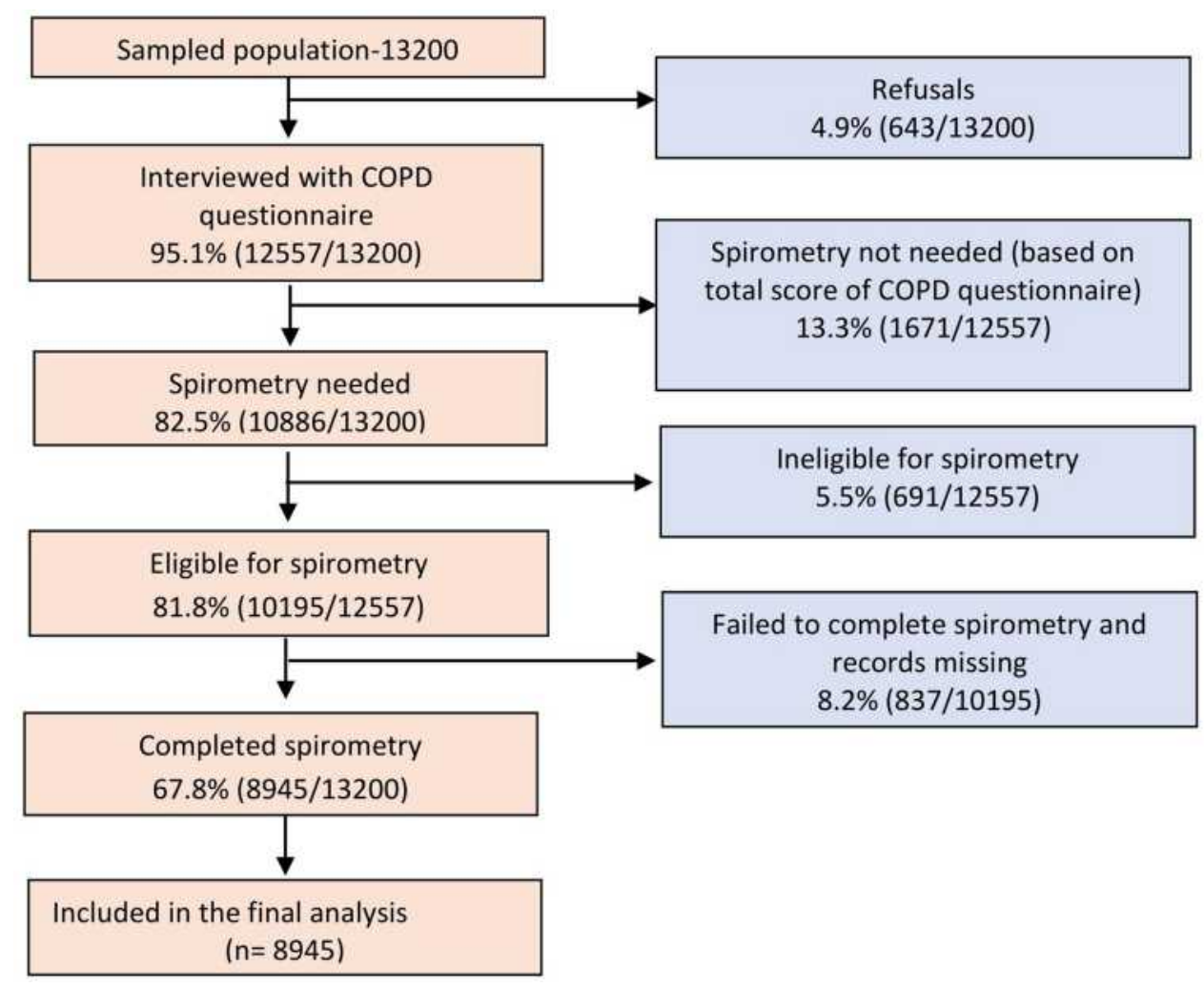

Figure I Flow diagram of the study.

participant with a maximum of eight attempts. Participants who had obstructive lung diseases (FEV1/FVC $<0.7)$ were given Asthalin ${ }^{\circledR}$ Salbutamol (400 microns, Cipla) through a metered-dose inhaler, and post-bronchodilator spirometry readings were taken maintaining the American Thoracic Society and European Respiratory Society (ATS/ERS) standards. ${ }^{22}$ Participants who could not perform spirometry despite eight attempts were documented as "could not perform" (CNP). The definition of COPD proposed by the Global Initiative for Chronic Obstructive Lung Diseases (GOLD), 'a post-bronchodilator FEV1/ FVC (forced expiratory volume in $1 \mathrm{~s} /$ forced vital capacity) ratio below $0.70^{\prime}$ was taken for this study. ${ }^{23}$ The severity of COPD was determined by the GOLD criteria. The obstruction was diagnosed by assessing airflow limitation. The severity of COPD was also determined by the GOLD criteria post-bronchodilator $\mathrm{FEV}_{1}$ (Mild $\mathrm{FEV}_{1} \geq 80 \%$ of predicted, Moderate $\mathrm{FEV}_{1} \geq 50$ to $\leq 80 \%$ of predicted, Severe FEV $1 \geq 30$ to $\leq 50 \%$ of predicted and Very Severe $\mathrm{FEV}_{1} \leq 30 \%$ of predicted). Furthermore, COPD diagnosis was confirmed based on spirometry readings by a respiratory physician (pulmonologist). Although the prime focus of this study was on COPD, restrictive defect is common while conducting spirometry and defined as an FEV1/FVC $\geq 70$ and an $\mathrm{FVC}<80 \%$ predicted. ${ }^{24}$ We have also recorded a substantial proportion of restrictive defect in this study.

\section{Explanatory Variables}

The explanatory variables of interest for this study included health, lifestyle and sociodemographic data. Health and lifestyle indicators included smoking status (smoker, nonsmoker), number of cigarette packs consumed per year (0-14, 15-24, 25-49, 50+), and BMI (underweight, normal weight, overweight and obese). Sociodemographic characteristics of the participants included ethnicity (upper caste group, disadvantaged Janajatis, relatively advantaged Janajatis, disadvantaged non-Dalit Terai caste, Dalit and religious minorities), sex (male, female), age (20-39 years old, 40-59 years old, and 60 years or older), education (illiterate/no formal schooling, below secondary school level $[<10$ years of formal education], secondary school and above [ $\geq 10$ years of formal education]) and provinces of residence (Province 1, Province 2, Bagmati Province, Province 5, Gandaki Province, Karnali Province, Sudurpashchim Province). 


\section{Data Management and Analysis}

We used android mobile phones inbuilt with data collection software (Research and Monitoring - REMO software) to collect data digitally, including that of the face-to-face interviews and spirometry readings. Spirometry readings from the field were sent to a respiratory physician for confirmation of COPD. Different categories were assigned to the readings, from 0 for normal to 8 for very severe conditions of obstruction and restriction. Data from the readings were entered in separate EpiData files with unique participant IDs and later merged with the main data set from the field. Data cleaning including the correction of inconsistencies was performed in SPSS version 16.0. Data were then exported to Stata version 13 for analysis. To adjust for unequal distribution of selection and to adjust for non-response, all the estimation was done based on sampling weight. We present our results as percentages and odds ratio (including both unadjusted and adjusted odds ratio) with $95 \%$ confidence intervals (CI). We conducted a bivariate analysis to analyze the association between each explanatory variable and COPD prevalence. To be included in multivariable modeling, we considered $\mathrm{P} \leq 0.25$ as statistically significant for each variable. We further assessed multicollinearity (variance inflation factor with a value $>1$ ) for all independent variables found to be statistically significant from the bivariate analysis and then conducted multivariable logistic regression with COPD prevalence as a dependent variable using the independent variables identified as statistically significant in the bivariate analysis.

\section{Results}

The sociodemographic characteristics of the study population by age, sex, ethnicity, education, province, and place of residence are presented in Table 1. More than two-fifth (42.8\%) of the participants belonged to the age-group of 40-59 years. More females than males participated in the study (57.4\% versus $42.6 \%)$. The majority $(54.5 \%)$ of participants were illiterate and had no formal schooling. More people belonged to the upper caste group (34.1\%) which was followed by disadvantaged Janajatis $(21.0 \%)$. About onefourth of the participants were from Bagmati Province (24.7\%) followed by Province 5 (17.4\%), Province 1 (16.8\%), Province 2 (16.5\%), Gandaki Province (10.3\%), Sudurpashchim Province (9.1\%), and Karnali Province $(5.2 \%)$. More than half $(51.5 \%)$ of the participants lived in rural areas.
Table I Socio-Demographic Characteristics of the Study Population $(\mathrm{N}=8945)$

\begin{tabular}{|l|r|r|}
\hline Characteristics & N & $\%$ \\
\hline Age & 3080 & \\
$20-39$ & 3824 & 34.4 \\
$40-59$ & 2041 & 42.8 \\
60 years and above & & 22.8 \\
\hline Sex & 3807 & \\
Male & 5138 & 42.6 \\
Female & & 57.4 \\
\hline Ethnicity & 3049 & \\
Upper caste group & 1878 & 34.1 \\
Disadvantaged Janajati & 1504 & 21.0 \\
Relatively advantaged Janajati & 1355 & 16.8 \\
Disadvantaged non-Dalit Terai caste & 905 & 15.1 \\
Dalit & 254 & 10.1 \\
Religious minorities & 2.8 \\
\hline Education & 4611 & \\
Illiterate/No formal schooling & 4334 & 48.5 \\
Below secondary (<10 years) & 4876 & 54.5 \\
Secondary and above ( $\geq 10$ years) & 2064 & 23.1 \\
\hline Province & 2005 & 22.4 \\
Province I & & \\
Province 2 & 1504 & 16.8 \\
Bagmati Province & 1473 & 16.5 \\
Gandaki Province & 2211 & 24.7 \\
Province 5 & & 10.3 \\
Karnali Province & & 17.4 \\
Sudurpaschim Province & & 5.2 \\
\hline Place of residence & & \\
Rural & & \\
Urban & & \\
\hline
\end{tabular}

The classification of COPD based on GOLD criteria is presented in Table 2. According to these criteria, 3.9\% were classified as having mild obstruction (GOLD I), $5.4 \%$ moderate obstruction (GOLD II), $1.7 \%$ severe obstruction (GOLD III) and $0.6 \%$ as very severe obstruction (GOLD IV).

The overall prevalence and descriptive statistics of COPD in our study population are summarized in Table 3. The overall prevalence of COPD in Nepal was $11.7 \%$ (95\% CI:10.5-12.9). We found a higher prevalence of COPD (16.8\% [95\% CI: 14.9-18.8]) among current smokers compared to non-smokers $(9.1 \%$ [95\% CI: $7.9-$ $10.5]$ ), and the prevalence increased with higher reported numbers of cigarette packs per year of smoking. Similarly, those individuals classified as underweight 
Table 2 Classification of COPD Based on GOLD Criteria

\begin{tabular}{|l|r|r|r|}
\hline Categories & Number & Percentage & 95\% Cl \\
\hline Normal & 6973 & 77.2 & $75.5-78.8$ \\
Restrictive defects & 970 & 11.2 & $9.8-12.8$ \\
GOLD I: Mild obstruction & 330 & 3.9 & $3.4-4.6$ \\
GOLD II: Moderate & 473 & 5.4 & $4.7-6.2$ \\
obstruction & 143 & 1.7 & $1.4-2.1$ \\
GOLD III: Severe & & & \\
obstruction & 56 & 0.6 & $0.4-0.9$ \\
GOLD IV: Very severe & & & \\
obstruction & & & \\
\hline
\end{tabular}

had a higher prevalence of COPD, ie, $21.7 \%$ (95\% CI: 18.5-25.4) whereas those who were overweight had only $7.7 \%$ (95\% CI: 6.4-9.3). The prevalence of COPD by sex was similar with $12.5 \%$ (95\% CI: 11.1-14.1) among males and $11.0 \%$ (95\% CI: 9.6-12.4) among females. In terms of age, individuals aged 60 years and above had the highest prevalence of $21.6 \%$ (95\% CI: 19.3-24.1) among the age groups. By ethnicity, the prevalence ranged from 9.3\% (95\% CI: 7.7-11.1) among disadvantaged Janajatis to $15.2 \%$ (95\% CI: 11.9-19.2) among disadvantaged non-Dalit Terai caste groups. The prevalence of COPD among participants who were illiterate and/or had no formal schooling was $15.7 \%$ (95\% CI: $14.1-$ 17.6). Among participants with secondary education and above, COPD prevalence was 5.2\% (95\% CI: 4.2-6.5). The prevalence of COPD varied considerably also by province, ranging from $6.0 \%(95 \% \mathrm{CI}: 4.0-8.9)$ in Gandaki Province to $25.1 \%$ (95\% CI: 18.1-33.8) in Karnali Province. In terms of residence, the prevalence of COPD was almost identical with $11.7 \%$ (95\% CI: 10.0-13.6) among those residing in rural and $11.7 \%$ (95\% CI: 10.1-13.4) among those residing in urban areas of Nepal. The distribution of COPD prevalence for provinces stratified by sex and area of residence is shown in Figure 2.

\section{Factors Associated with COPD}

A summary of bivariate and multivariable analyses is presented in Table 4. Initially, a bivariate analysis was conducted with COPD prevalence as the dependent variable and individual background characteristics and risk factors as independent variables. The odds of having COPD were estimated for nine factors: age, sex, ethnicity, education, province, BMI, smoking, packs per year, and area of residence (Table 4). Out of these variables, all
Table 3 Descriptive Characteristics of Participants with COPD $(\mathrm{N}=8945)$

\begin{tabular}{|c|c|c|c|c|}
\hline \multirow{2}{*}{$\begin{array}{l}\text { Characteristics } \\
\text { Socio-Demographic } \\
\text { Characteristics }\end{array}$} & \multirow{2}{*}{$\begin{array}{c}\text { Total } \\
\mathbf{N}\end{array}$} & \multicolumn{2}{|c|}{ COPD } & \multirow[t]{2}{*}{$95 \% \mathrm{Cl}$} \\
\hline & & $\mathbf{n}$ & $\%$ & \\
\hline \multicolumn{5}{|l|}{ Age } \\
\hline $20-39$ & 3080 & 197 & 6.2 & $4.9-7.7$ \\
\hline $40-59$ & 3824 & 386 & 10.5 & $9.1-12.1$ \\
\hline 60 years and above & $204 I$ & 426 & 21.6 & 19.3-24.1 \\
\hline \multicolumn{5}{|l|}{ Sex } \\
\hline Male & 3807 & 478 & 12.5 & $11.1-14.1$ \\
\hline Female & 5138 & 531 & 11.0 & $9.6-12.4$ \\
\hline \multicolumn{5}{|l|}{ Ethnicity } \\
\hline Upper caste group & 3049 & 335 & 11.6 & $9.9-13.5$ \\
\hline Disadvantaged Janjati & 1878 & 177 & 9.3 & 7.7-11.1 \\
\hline Relatively advantaged Janjati & 1504 & $15 \mid$ & 10.2 & $8.3-12.5$ \\
\hline $\begin{array}{l}\text { Disadvantaged non-Dalit Terai } \\
\text { caste }\end{array}$ & 1355 & 200 & 15.2 & $11.9-19.2$ \\
\hline Dalit & 905 & 114 & 13.4 & $10.4-17.2$ \\
\hline Religious minorities & 254 & 32 & 12.4 & $8.0-18.6$ \\
\hline \multicolumn{5}{|l|}{ Education } \\
\hline Illiterate/No formal schooling & 4876 & 722 & 15.7 & $14.1-17.6$ \\
\hline Below secondary ( $<10$ years) & 2064 & 186 & 9.0 & $7.6-10.6$ \\
\hline $\begin{array}{l}\text { Secondary and above }(\geq 10 \\
\text { years) }\end{array}$ & 2005 & 101 & 5.2 & $4.2-6.5$ \\
\hline \multicolumn{5}{|l|}{ Province } \\
\hline Province I & 1504 & 92 & 6.2 & $4.8-8.0$ \\
\hline Province 2 & 1473 & 240 & 16.4 & 13.2-20.3 \\
\hline Bagmati Province & 2211 & 253 & 11.7 & $9.7-14.1$ \\
\hline Gandaki Province & 921 & 56 & 6.0 & $4.0-8.9$ \\
\hline Province 5 & 1559 & 145 & 9.5 & $7.5-11.8$ \\
\hline Karnali Province & 462 & 109 & 25.1 & $18.1-33.8$ \\
\hline Sudurpaschim Province & 815 & 114 & 14.3 & $11.8-17.3$ \\
\hline \multicolumn{5}{|l|}{ Place of residence } \\
\hline Rural & 4611 & 523 & 11.7 & $10.0-13.6$ \\
\hline Urban & 4334 & 486 & 11.7 & $10.1-13.4$ \\
\hline \multicolumn{5}{|l|}{ Lifestyle characteristics } \\
\hline Smokers & 2990 & 482 & 16.8 & $14.9-18.8$ \\
\hline Non-smokers & 5955 & 527 & 9.1 & $7.9-10.5$ \\
\hline \multicolumn{5}{|l|}{ Packs per year } \\
\hline $0-14$ & 8210 & 847 & 10.7 & $9.5-11.9$ \\
\hline $15-24$ & 280 & 58 & 22.1 & $16.9-28.2$ \\
\hline $25-49$ & 234 & 52 & 21.3 & | $5.7-28.2$ \\
\hline $50+$ & 221 & 52 & 25.5 & $19.6-32.5$ \\
\hline \multicolumn{5}{|l|}{ BMI } \\
\hline Underweight & 1108 & 247 & 21.7 & $18.5-25.4$ \\
\hline Normal & 5619 & 600 & 11.3 & $10.0-12.7$ \\
\hline Overweight & 2218 & 162 & 7.7 & $6.4-9.3$ \\
\hline
\end{tabular}



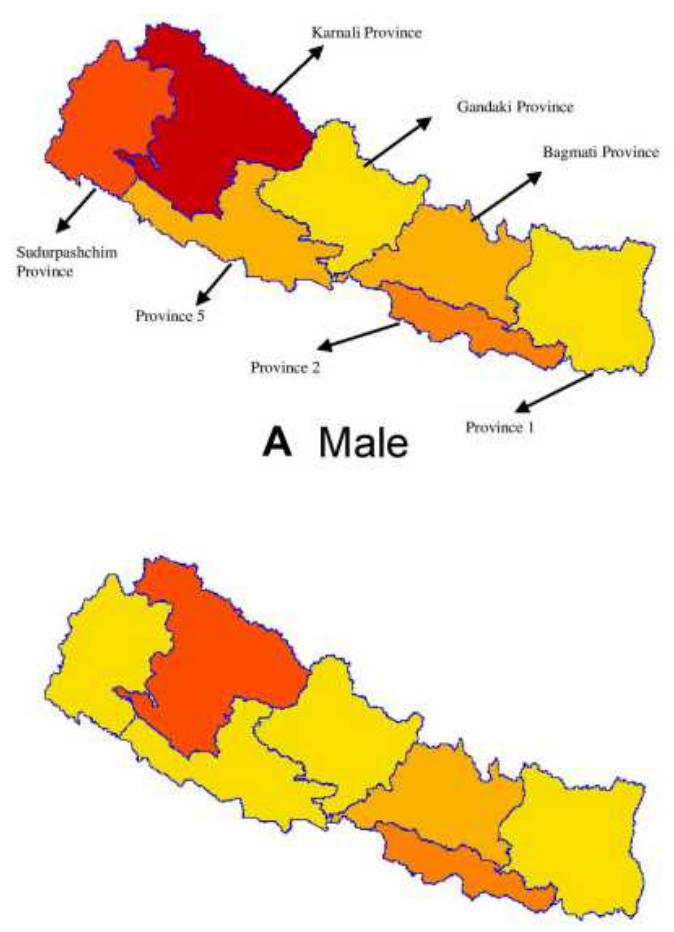

B Female

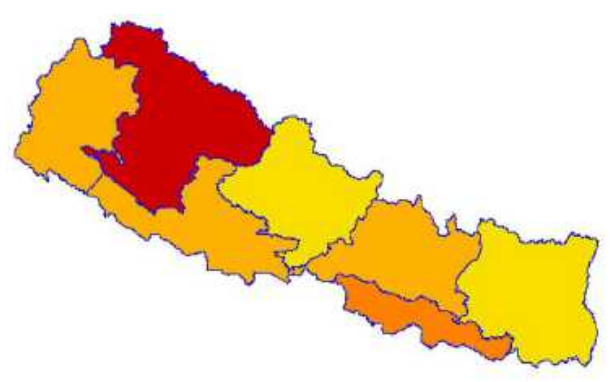

C Urban

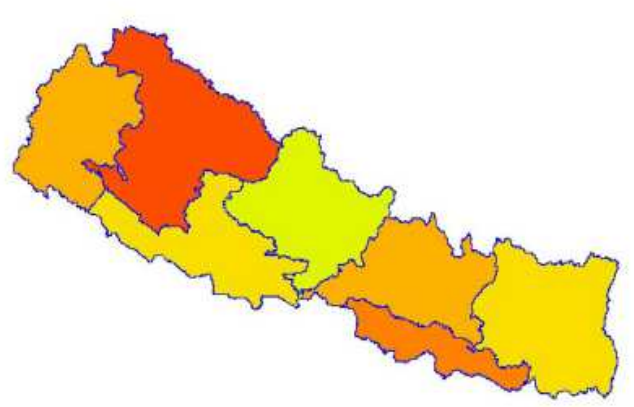

D Rural

Figure 2 Geographical distribution of COPD prevalence by sex and residence in Nepal. The map is created using GMAP procedure in SAS 9.4.

except the area of residence had $p$ value $<0.25$ in bivariate analysis, which were then taken to the multivariable analysis.

A summary of the multivariable logistic regression analysis of COPD prevalence shows that smoking, low education level, belonging to a disadvantaged non-Dalit Terai caste, higher age, a high number of cigarette packs consumed per year, being a resident of Karnali Province, and having a lower BMI, are associated with COPD. The results of our study show that participants aged 60 years or above had 3.1 times (95\% CI: 2.3-4.1) higher odds of having COPD compared to 20-39 years old individuals. Members of a disadvantaged non-Dalit Terai caste group had 1.5 times (95\% CI: 1.0-2.6) higher odds of having COPD compared to disadvantaged Janajatis, participants with residence in Karnali Province had 4.8 times (95\% CI: 2.6-8.9) higher odds of having COPD compared to those of Gandaki province, and those who were illiterate and/or without formal schooling had higher odds ( $\mathrm{OR}=2.0 ; 95 \%$ CI: 1.5-2.7) of having COPD compared to participants with secondary or higher education ( $\geq 10$ years). Current smokers had higher odds (OR: 1.3; 95\% CI: 1.1-1.7) of having COPD compared to non-smokers; participants who were classified as underweight by BMI had higher odds $(\mathrm{OR}=1.7 ; 95 \% \mathrm{CI}: 1.4-2.1)$ of having COPD and those with overweight had lower odds $(\mathrm{OR}=0.7 ; 95 \% \mathrm{CI}$ : 0.5-0.9) of having COPD compared to participants with a normal BMI. Likewise, persons who consumed 50 or more packs of cigarettes per year had 1.7 (95\% CI: 1.1-2.4) times higher odds of having COPD compared to those who reported $0-14$ packs per year of smoking.

\section{Discussion}

The findings presented here are the results of the first nationwide population-based prevalence study on COPD and associated factors in Nepal. They show that the COPD prevalence of adults aged 20 years and above in Nepal is $11.7 \%$, with nearly four-fold higher prevalence in Karnali Province (25.1\%) compared to Gandaki Province (6.0\%). A higher rate of COPD can be attributed mainly to the use of biomass fuels in poorly ventilated houses, a relatively higher rate of smoking and indoor air pollution, ${ }^{25}$ and lower availability of COPD services in Karnali Province which is the least developed province of Nepal in terms of Human Development Index. 
Table 4 Socio-Demographic and Lifestyle Factors Affecting Chronic Obstructive Pulmonary Diseases (COPD) in Nepal ( $n=8945)$

\begin{tabular}{|c|c|c|c|c|c|}
\hline \multirow[t]{2}{*}{ Variables } & \multirow[t]{2}{*}{$\mathbf{N}$} & \multicolumn{3}{|c|}{ COPD } & \multirow[t]{2}{*}{ P value } \\
\hline & & n (\%) & OR $(95 \% \mathrm{Cl})$ & AOR 95\% Cl & \\
\hline \multicolumn{6}{|l|}{ Sociodemographic characteristics } \\
\hline \multicolumn{6}{|l|}{ Age (ref: $20-39$ years) } \\
\hline $20-39$ & 3080 & $197(6.2)$ & & & \\
\hline $40-59$ & 3824 & $386(10.5)$ & $1.8(1.4-2.3)$ & $1.5(1.2-1.9)$ & 0.002 \\
\hline 60 years and above & 2041 & $426(21.6)$ & $4.2(3.3-5.4)$ & $3.1(2.3-4.1)$ & 0.000 \\
\hline Sex (ref: female) & 5138 & $531(11.0)$ & & & \\
\hline Male & 3807 & $478(12.5)$ & $1.2(1.1-1.4)$ & $1.0(0.8-1.2)$ & $0.84 I$ \\
\hline Ethnicity (ref: disadvantaged Janajati) & 1878 & $177(9.3)$ & & & \\
\hline Upper caste group & 3049 & $335(11.7)$ & $1.3(0.1-1.7)$ & $1.3(1.0-1.7)$ & 0.047 \\
\hline Relatively advantaged Janajati & 1504 & $15 \mathrm{I}(10.2)$ & I.I (0.8-1.5) & $1.2(0.9-1.6)$ & 0.281 \\
\hline Disadvantaged non-Dalit Terai caste & 1355 & $200(15.2)$ & $1.8(1.2-2.5)$ & $1.5(1.0-2.6)$ & 0.029 \\
\hline Dalit & 905 & $114(13.4)$ & $1.5(I . I-2.1)$ & $1.2(0.9-1.7)$ & 0.196 \\
\hline Religious minorities & 254 & $32(12.4)$ & $1.4(0.8-2.3)$ & $1.2(0.7-2.1)$ & 0.441 \\
\hline Education (ref: secondary and above) & 2005 & I0I (5.2) & & & \\
\hline Illiterate/no formal schooling & 4876 & $722(15.7)$ & $3.4(2.7-4.4)$ & $2.0(1.5-2.7)$ & 0.000 \\
\hline Below secondary (<10 years) & 2064 & $186(9.0)$ & $1.8(1.4-2.4)$ & $1.5(1.1-2.1)$ & 0.005 \\
\hline Province (ref: Gandaki Province) & 921 & $56(6.0)$ & & & \\
\hline Province I & 1504 & $92(6.2)$ & $1.0(0.6-1.7)$ & $1.0(0.6-1.8)$ & 0.937 \\
\hline Province 2 & 1473 & $240(16.4)$ & $3.1(1.9-5.1)$ & $2.6(1.5-4.5)$ & 0.001 \\
\hline Bagmati Province & 2211 & $253(11.7)$ & $2.1(1.2-3.3)$ & $2.2(1.4-3.7)$ & 0.002 \\
\hline Province 5 & 1559 & $145(9.5)$ & $1.6(1.0-2.7)$ & $1.6(0.9-2.7)$ & 0.091 \\
\hline Karnali Province & 462 & $109(25.1)$ & $5.3(2.9-9.7)$ & $4.8(2.6-8.9)$ & 0.000 \\
\hline Sudurpaschim Province & 815 & $114(14.3)$ & $2.6(1.6-4.2)$ & $2.4(1.4-3.9)$ & 0.001 \\
\hline \multicolumn{6}{|l|}{ Lifestyle characteristics } \\
\hline Smoking status (ref: non-smokers) & 5955 & $527(9.1)$ & & & \\
\hline Smokers & 2990 & $482(16.8)$ & $2.0(1.7-2.4)$ & $1.3(1.1-1.7)$ & 0.006 \\
\hline Packs per year (ref: 0-14) & 8210 & $847(10.7)$ & & & \\
\hline $15-24$ & 280 & $58(22.1)$ & $2.4(1.7-3.3)$ & $1.3(0.9-1.9)$ & 0.102 \\
\hline $25-49$ & 234 & $52(21.3)$ & $2.3(1.6-3.3)$ & $1.3(0.9-1.9)$ & 0.198 \\
\hline $50+$ & 221 & $52(25.5)$ & $2.9(2.0-4.1)$ & $1.7(1.1-2.4)$ & 0.009 \\
\hline BMI (ref: normal) & 5619 & $600(11.3)$ & & & \\
\hline Underweight & 1108 & $247(21.7)$ & $2.2(1.8-2.7)$ & $1.7(1.4-2.1)$ & 0.000 \\
\hline Overweight & 2218 & $162(7.7)$ & $0.7(0.5-0.8)$ & $0.7(0.5-0.9)$ & 0.002 \\
\hline
\end{tabular}

The COPD prevalence in Nepal, $11.7 \%$ based on the post-bronchodilator FEV1/FVC $<70 \%$ criterion, is within the range found in other studies conducted in Japan, Morocco, Portugal, and Italy, ${ }^{26-29}$ but higher than the prevalence of $8.2 \%$ in China, ${ }^{30}$ lower than the prevalence of $17.2 \%$ observed in Korea ${ }^{31}$ and $17.5 \%$ in Tanzania, ${ }^{32}$ and similar to $13.5 \%$ in Bangladesh. ${ }^{33} \mathrm{~A}$ populationbased study using the Burden of Obstructive Lung Disease criteria which employed spirometry measurements to estimate the prevalence of COPD in 12 countries $^{34}$ reported similar COPD estimates (globally 10.1\%; participating Asian countries 11.4-13.9\%) in line with the results of our study. This study showed that males had a slightly higher COPD prevalence than females $(12.5 \%$ in males and $11.0 \%$ in females) and the finding is similar with other studies in Bangladesh and China that males had a higher prevalence than females. ${ }^{30,33}$ 
Our study reveals that the prevalence of COPD in Nepal is higher among persons of older age and among current smokers. These results are consistent with those of population-based studies conducted in China ${ }^{30}$ and Bangladesh, ${ }^{33}$ and in line with the international epidemiology of $\mathrm{COPD}^{35}$ the prevalence of COPD was higher among participants who were illiterate and/or had no formal schooling compared to those with secondary and higher education ( $\geq 10$ years) which is similar to the results reported by Kanervisto et al. ${ }^{36}$ Interestingly, our study documents great variation in the prevalence of COPD between the different provinces of Nepal. Overall, COPD prevalence was the highest in Karnali Province, with $25 \%$ among the seven provinces in Nepal and the national average was $11.7 \%$. This higher prevalence of COPD may be due to more widespread or heavier cigarette smoking and the use of solid biomass fuels in poorly ventilated rooms as the main source for cooking. ${ }^{37}$ The findings from our study indicated a higher prevalence of COPD among disadvantaged non-Dalit Terai caste group and upper caste compared to disadvantaged Janajatis. Similar to this finding, a study conducted in the midwestern region of Nepal reported a higher proportion of COPD among the socially disadvantaged group (Dalit) against Janajatis. 9 The higher prevalence among this group may be attributed to factors, such as low educational level, low level of awareness and their economic status, which may affect their health service utilization. Our data also show a negative association between BMI and COPD prevalence in Nepal which is consistent with the literature. ${ }^{38}$

As found and supported in other studies ${ }^{29,30,39}$ there was also a positive trend with the increase of cigarette packs per year, confirming smoking as a significant risk factor for the development of COPD. In fact, above 50 pack-years COPD prevalence almost tripled if compared to $0-14$ packs per year ( $10.4 \%$ versus $25.5 \%)$, highlighting the dramatic burden of cigarette smoke-related health care resource utilization and costs in Nepal.

Various risk factors have been associated with COPD. It is well known that smoking is the major known risk factor for developing COPD. ${ }^{40-42}$ As expected, this study also found that participants with higher smoking rates had a higher prevalence of COPD in Nepal. Age is another well-established risk factor for COPD, and our study also depicts the same. We observed a nearly three times higher prevalence of COPD among individuals aged 60 years or above compared to individuals aged 20 to 39 years. This is in line with the results reported in previous studies. ${ }^{35,43}$

The present study has several strengths: First of all, as a large-scale and population-based study with a high overall response rate, it used home visits to estimate the prevalence of COPD in Nepal and ensure that the study results are representative at the sub-national level. While many other studies on COPD included adults over 40 years of age only, ${ }^{44}$ this study included adults aged 20 years and above to avoid missing any people with airflow obstruction.

Secondly, epidemiological studies that rely on physician diagnosis or patient-reported physician diagnosis, without lung function assessment (ie, use of spirometry), usually underestimate the prevalence of COPD. ${ }^{45}$ To overcome this, COPD diagnostic questionnaires were used for screening COPD cases in this study together with highquality control of the performance of spirometry which resulted in a good reproducibility of spirometry.

However, this study also has some limitations: firstly, we used the fixed FEV1/FEV ratio to diagnose COPD which may lead to over and under-diagnosis in older and younger adults, respectively. ${ }^{46}$ Similarly, postbronchodilator spirometry was not performed for all study participants. We also lack information about environmental exposure, such as solid biomass fuel use, which could be used to quantify the effects of these factors on COPD. Finally, the cross-sectional nature of the study did not allow us to establish a causal relationship between COPD and associated factors.

\section{Conclusion}

This first nationwide, population-based study using spirometry revealed that COPD remains a huge hidden burden of high-prevalence disease in Nepal. Cigarette smoking, older age, lower BMI, low educational attainment, having smoked more than 50 pack-years, province of residence, and ethnicity, are major risk factors for COPD in Nepal. The prevention and early detection of COPD using spirometry and relevant public health interventions based on risk factors should become a public health priority in Nepal to reduce the high COPD-related morbidity and mortality in the country.

\section{Disclosure}

The authors report no conflicts of interest in this work. 


\section{References}

1. Global initiative for Chronic Obstructive Pulmonary Diseases. Global strategy for the diagnosis, management and prevention of COPD, 2018. 2018.

2. Lozano R, Naghavi M, Foreman K, et al. Global and regional mortality from 235 causes of death for 20 age groups in 1990 and 2010: a systematic analysis for the Global Burden of Disease Study 2010. Lancet. 2012;380(9859):2095-2128. doi:10.1016/S0140-6736(12) 61728-0

3. Institute of Health Metrics and Evaluation (IHME). GBD compare data visualization Seattle. WA: IHME, University of Washington; 2017. Available from: https://vizhub.healthdata.org/gbd-compare/. Accessed March 24, 2021.

4. World Health Organization. Chronic obstructive pulmonary diseases, fact sheet. 2013.

5. Worl Health Organization, Control RfIT. WHO report on the global tobacco epidemic, 2008: the MPOWER package: World Health Organization. 2008.

6. Bloom DE, Cafiero E, Jané-Llopis E, et al. The global economic burden of noncommunicable diseases. Program on the Global Demography of Aging. 2012.

7. Bhandari GP, Angdembe MR, Dhimal M, Neupane S, Bhusal C. State of non-communicable diseases in Nepal. BMC Public Health. 2014;14(1):23. doi:10.1186/1471-2458-14-23

8. Pokharel B, Humagain S, Pant P, Gurung R, Koju R, Bedi T. Spectrum of diseases in a medical ward of a teaching hospital in a developing country. J Coll Med Sci Nepal. 2012;8(2):7-11. doi:10.3126/jcmsn.v8i2.6831

9. Bhandari R, Sharma R. Epidemiology of chronic obstructive pulmonary disease: a descriptive study in the mid-western region of Nepal. Int J Chron Obstruct Pulmon Dis. 2012;7:253. doi:10.2147/COPD. S28602

10. Soriano JB, Abajobir AA, Abate KH, et al. Global, regional, and national deaths, prevalence, disability-adjusted life years, and years lived with disability for chronic obstructive pulmonary disease and asthma, 1990-2015: a systematic analysis for the Global Burden of Disease Study 2015. Lancet Respir Med. 2017;5(9):691-706. doi:10.1016/S2213-2600(17)30293-X

11. Lopez AD, Mathers CD, Ezzati M, Jamison DT, Murray CJ. Global Burden of Disease and Risk Factors. The World Bank; 2006.

12. Karki KB, Dhakal P, Shrestha SL, et al. Situation Analysis of Ambient Air Pollution and Respiratory Health Effects in Kathmandu Valley. Nepal Health Research Council; 2016.

13. Kim BM, Park J-S, Kim S-W, et al. Source apportionment of PM10 mass and particulate carbon in the Kathmandu Valley, Nepal. Atmos Environ. 2015;123:190-199. doi:10.1016/j.atmosenv.2015.10.082

14. Sreeramareddy CT, Ramakrishnareddy N, Kumar HH, Sathian B, Arokiasamy JT. Prevalence, distribution and correlates of tobacco smoking and chewing in Nepal: a secondary data analysis of Nepal Demographic and Health Survey-2006. Subst Abuse Treat Prev Policy. 2011;6(1):33. doi:10.1186/1747-597X-6-33

15. Ministry of Health Nepal NE, ICF. Nepal Demographic and Health Survey 2016. Kathmandu; 2016.

16. Halbert R, Isonaka S, George D, Iqbal A. Interpreting COPD prevalence estimates: what is the true burden of disease? Chest. 2003;123(5):1684-1692. doi:10.1378/chest.123.5.1684

17. Government of Nepal, National Planning Commision. Nepal's sustainable development goals, baseline report. 2017.

18. Dhimal M, Karki KB, Sharma SK, et al. Prevalence of selected chronic non-communicable diseases in Nepal. J Nepal Health Res Counc. 2019;17(3):394-401. doi:10.33314/jnhrc.v17i3.2327

19. Nemeth R, editor. Respondent selection within the household-a modification of the Kish grid. Meeting of Young Statisticians. 2002.
20. Stanley AJ, Hasan I, Crockett AJ, Van Schayck OC, Zwar NA COPD Diagnostic Questionnaire (CDQ) for selecting at-risk patients for spirometry: a cross-sectional study in Australian general practice. NPJ Prim Care Respir Med. 2014;24:14024. doi:10.1038/npjpcrm. 2014.24

21. Price DB, Tinkelman DG, Nordyke RJ, Isonaka S, Halbert R. Scoring system and clinical application of COPD diagnostic questionnaires. Chest. 2006;129(6):1531-1539. doi:10.1378/chest.129.6.1531

22. Miller MR, Hankinson J, Brusasco V, et al. Standardisation of spirometry. Eur Respir J. 2005;26(2):319-338. doi:10.1183/090 31936.05.00034805

23. Global Initiative for Chronic Obstructive Lung Disease (GOLD). Spirometry for health care providers 2010.

24. Soriano JB, Miravitlles M, García-Río F, et al. Spirometricallydefined restrictive ventilatory defect: population variability and individual determinants. Prim Care Respir J. 2012;21(2):187-193. doi:10.4104/pcrj.2012.00027

25. Ghimire S, Mishra SR, Sharma A, Siweya A, Shrestha N, Adhikari B. Geographic and socio-economic variation in markers of indoor air pollution in Nepal: evidence from nationally-representative data. BMC Public Health. 2019;19(1):195. doi:10.1186/s12889-0196512-Z

26. Fukuchi Y, Nishimura M, Ichinose M, et al. COPD in Japan: the Nippon COPD epidemiology study. Respirology. 2004;9(4):458-465. doi:10.1111/j.1440-1843.2004.00637.x

27. El Rhazi K, Nejjari C, BenJelloun M, El Biaze M, Attassi M, GarciaLarsen V. Prevalence of chronic obstructive pulmonary disease in Fez, Morocco: results from the BOLD study. Int J Tuberc Lung Dis. 2016;20(1):136-141. doi:10.5588/ijtld.15.0029

28. Barbara C, Rodrigues F, Dias H, et al. Chronic obstructive pulmonary disease prevalence in Lisbon, Portugal: the burden of obstructive lung disease study. Revista Portuguesa De Pneumologia. 2013;19 (3):96-105. doi:10.1016/j.rppnen.2012.11.001

29. Guerriero M, Caminati M, Viegi G, Senna G, Cesana G, Pomari C. COPD prevalence in a north-eastern Italian general population. Respir Med. 2015;109(8):1040-1047. doi:10.1016/j.rmed.2015.05.009

30. Zhong N, Wang C, Yao W, et al. Prevalence of chronic obstructive pulmonary disease in China: a large, population-based survey. $\mathrm{Am}$ $J$ Respir Crit Care Med. 2007;176(8):753-760. doi:10.1164/ recm.200612-1749OC

31. Kim DS, Kim YS, Jung K-S, et al. Prevalence of chronic obstructive pulmonary disease in Korea: a population-based spirometry survey. Am J Respir Crit Care Med. 2005;172(7):842-847. doi:10.1164/ rccm.200502-259OC

32. Magitta N, Walker RW, Apte KK, et al. Prevalence, risk factors and clinical correlates of COPD in a rural setting in Tanzania. Eur Respir J. 2018;51(2):1700182. doi:10.1183/13993003.00182-2017

33. Alam DS, Chowdhury MA, Siddiquee AT, Ahmed S, Clemens JD. Prevalence and determinants of chronic obstructive pulmonary disease (COPD) in Bangladesh. COPD. 2015;12(6):658-667.

34. Lim S, Lam DC-L, Muttalif AR, et al. Impact of chronic obstructive pulmonary disease (COPD) in the Asia-Pacific region: the EPIC Asia population-based survey. Asia Pac Fam Med. 2015;14(1):4. doi:10.1186/s12930-015-0020-9

35. Anto J, Vermeire P, Vestbo J, Sunyer J. Epidemiology of chronic obstructive pulmonary disease. Eur Respir J. 2001;17(5):982-994. doi:10.1183/09031936.01.17509820

36. Kanervisto M, Vasankari T, Laitinen T, Heliövaara M, Jousilahti P, Saarelainen S. Low socioeconomic status is associated with chronic obstructive airway diseases. Respir Med. 2011;105(8):1140-1146. doi:10.1016/j.rmed.2011.03.008

37. Nepal Go, National Planning Commission CBoS. Environment statistics of Nepal. Kathmandu. 2019.

38. Soler J, Sanchez L, Roman P, Martinez M, Perpina M. Prevalence of malnutrition in outpatients with stable chronic obstructive pulmonary disease. Archivos de Bronconeumología. 2004;40(6):250-258. 
39. Caballero A, Torres-Duque CA, Jaramillo C, et al. Prevalence of COPD in five Colombian cities situated at low, medium, and high altitude (PREPOCOL study). Chest. 2008;133(2):343-349. doi:10. 1378/chest.07-1361

40. Løkke A, Lange P, Scharling H, Fabricius P, Vestbo J. Developing COPD: a 25 year follow up study of the general population. Thorax. 2006;61(11):935-939. doi:10.1136/thx.2006.062802

41. Xu F, Yin X, Zhang M, Shen H, Lu L, Xu Y. Prevalence of physician-diagnosed COPD and its association with smoking among urban and rural residents in regional mainland China. Chest. 2005;128(4):2818-2823. doi:10.1378/chest.128.4.2818

42. Ezzati M, Lopez AD. Estimates of global mortality attributable to smoking in 2000. Lancet. 2003;362(9387):847-852. doi:10.1016/ S0140-6736(03)14338-3
43. Jarad N. Chronic obstructive pulmonary disease (COPD) and old age? Chron Respir Dis. 2011;8(2):143-151. doi:10.1177/147997231 1407218

44. Uzaslan E, Mahboub B, Beji M, et al. The burden of chronic obstructive pulmonary disease in the Middle East and North Africa: results of the BREATHE study. Respir Med. 2012;106:S45-S59. doi:10.1016/S0954-6111(12)70014-8

45. Bakke P, Rönmark E, Eagan T, et al. Recommendations for epidemiological studies on COPD. Eur Respir Soc. 2011;38:1261-1277. doi:10.1183/09031936.00193809

46. Swanney MP, Ruppel G, Enright PL, et al. Using the lower limit of normal for the FEV1/FVC ratio reduces the misclassification of airway obstruction. Thorax. 2008;63(12):1046-1051. doi:10.1136/thx. 2008.098483

\section{Publish your work in this journal}

The International Journal of COPD is an international, peer-reviewed journal of therapeutics and pharmacology focusing on concise rapid reporting of clinical studies and reviews in COPD. Special focus is given to the pathophysiological processes underlying the disease, intervention programs, patient focused education, and self management protocols. This journal is indexed on PubMed Central, MedLine and CAS. The manuscript management system is completely online and includes a very quick and fair peer-review system, which is all easy to use. Visit http://www.dovepress.com/testimonials.php to read real quotes from published authors. 